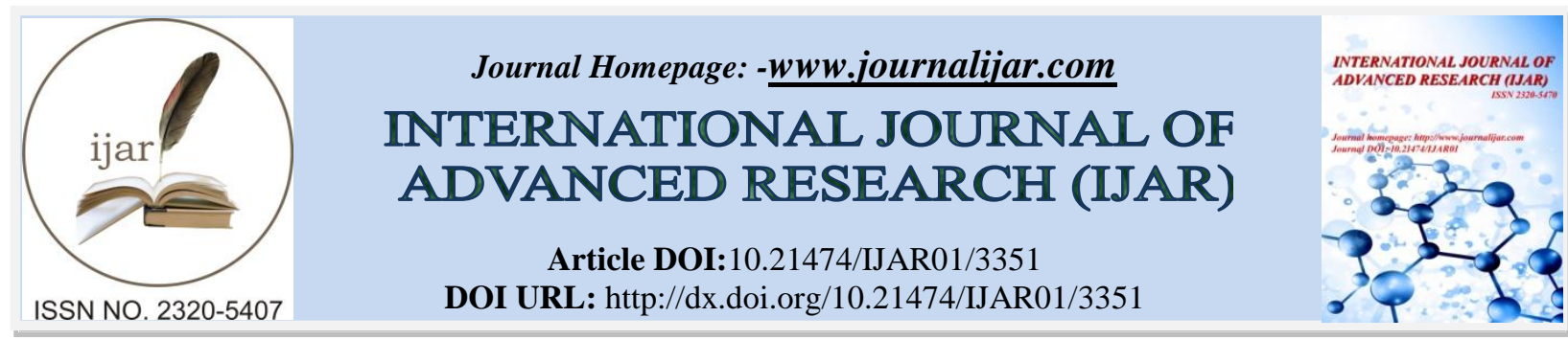

RESEARCH ARTICLE

\title{
MEASUREMENT OF PREOPERATIVE ANXIETY AND DETECTION OF PATIENTS' ANESTHETIC CONCERNS USING VAS.
}

Abdullah S. Alqefari, Abdullah A. alyami, Abdulmagid G. alenezi, Sultan A. Alsaleh, Tarik M. Almowald, Faisal M. Alturi, Mousa R. Alhokail, Mohammed A.Alqhtani, Jamal A.Alghamdi, Naif S.Alotaibi, Maha A. Alenezi, Mohammed A.Alkahmous, Abdulaziz A. Alkahmous and Omar A.Ahmed. GPs, College of Medicine, Jordanian University of Science and Technology (JUST), Riyadh, KSA.

\section{Manuscript Info}

Manuscript History

Received: 29 December 2016

Final Accepted: 22 January 2017

Published: February 2017

Key words:-

Anxiety, Preoperative anxiety, VAS, Assessing anxiety

\section{Abstract}

Background: Preoperative anxiety is unpleasant feeling; it is considered to be normal event in patients waiting for surgery. Preoperative anxiety has adverse effects on patients, recovery and outcomes of operation. It can cause delay in recovery, post-operative pain and nausea, also it may cause increasing in anesthesia dose given to patients. There are many factors increase anxiety before surgery; one is the gender, where females experience more anxiety than males. Preoperative anxiety can be decreased by increasing awareness of patients about surgery nature, anesthesia and the development in surgery techniques.

Aim: The objective of this study is to measure preoperative anxiety and identifies certain patient characteristics that predispose to high anxiety, and describes the quantity and quality of anxiety that patients experience preoperatively.

Methods: This study was conducted on 190 patients post operatively. A visual analogue scale questionnaire containing 10 questions was used to record patients, answers.

Results: Patients experienced preoperative anxiety with different degrees and woman was more anxious than man.

Conclusion: Preoperative anxiety is very common in candidates of surgery.

Copy Right, IJAR, 2017,. All rights reserved.

\section{Introduction:-}

Surgery is associated with patient anxiety. Anxiety is known as unpleasant feeling which may leads to avoidance of patient to perform planned operation (Yilmaz et al, 2011). Anxiety is a result of anticipation of threatening event (Hernández-Palazón et al, 2015), here operation is the event. Patients consider that day of surgery is the most threatening day in their lives (Nigussie et al, 2014). The time prior to operation is critical and it is a provoking cause for anxiety for patients (Johnston, 1989; Domar et al, 1989). Preoperative anxiety is a tension secondary to many events such as surgery, disease and hospitalization (Yilmaz et al, 2011). Preoperative anxiety represents $11 \%$ to $80 \%$ in adults (Maranets et al, 1999) it has higher effect on women especially young and it affects candidates of major surgery (Roomruangwong et al, 2012),patients without previous exposure to operations (Kim et al, 2010) and it differs according to type of surgery (Maranets et al, 1999). It was found that anxiety incidence in patients of cardiac surgery was 94\% (Hernández-Palazón et al, 2015), while other studies (Navarro-García et al, 2011; Martin et

Corresponding Author:-Abdullah S. Alqefari.

Address:-GPs, College of Medicine, Jordanian University of Science and Technology (JUST), Riyadh, KSA. 
al, 2004; Pochard et al, 1996; Underwood et al, 1993)reported that incidence rate of anxiety ranged from $20 \%$ to $35 \%$. Preoperative anxiety ranges from $60-90 \%$ in western population (Saini et al, 2016). Most candidates of surgery experience preoperative anxiety (Johnston, 1989; Domar et al, 1989; Badner et al, 1990). Actually preoperative anxiety is not unusual reaction of patient waiting for surgery (Yilmaz et al, 2011). Once the surgery is planned and determined,

patients' anxiety begins and it increases by entering hospital (Klopfenstein et al, 2000). There are many factors that can affect the degree of patients' anxiety including prior exposure to surgery, age, gender and education (Badner et al, 1990). Anxiety cause changes in sympathetic, parasympathetic and endocrine stimulation (Matthias et al, 2012). Preoperative anxiety is related to many adverse events such as delayed jaw relaxation, autonomic fluctuations, coughing during induction of anesthesia, increased pain, nausea and increased risk for infection (Nigussie et al, 2014). Anxious and non-anxious patients respond variously to anesthesia. Larger dosesof anesthesia andpostoperative drugs are required for anxious patients (Jafar et al, 2012), also they may need to stay longer in hospital (Matthias et al, 2012)because they experienced delay in recovery as a result of anxiety (Nigussie et al, 2014). Prolongation of mechanical ventilation also was mentioned (Hernández-Palazón et al, 2015), for all these reasons it is important to measure anxiety for those patients waiting for surgery. Visual Analogue Scale is one of many ways to evaluate anxiety (Jafar et al, 2012). It is used to evaluate anxiety preoperatively and it is a useful and easy method to be applied, also it allows determination of anxiety level in different surgical patients [Kindler et al, 2000; Boker et al, 2002; Millar et al, 1995; Oddershede et al, 2014; Perks et al, 2009; Shafer et al, 1996]. So the aim of this study is to measure preoperative anxiety before operation and describes the quantity of anxiety that patients experience preoperatively using visual analogue scale.

\section{Materials and Methods Subjects:-}

This cross sectional observational study was performed on 190 patients in the period from $20^{\text {th }}$ January 2017 to $7^{\text {th }}$ February 2017 from Yamama Hospital in Riyadh, an approval from the hospital was obtained to perform this study. This study was performed after operation, participants were asked to answer the questions they all agreed and welcomed. There was no exclusion in this study where all participants answered all questions.

\section{Patient Questionnaire:-}

A scored visual analogue scale questionnaire containing 10 questions was established to record the answers of patients and quantify anxiety. The score scale ranged from 0 to 10 , zero $=$ no anxiety while $10=$ extreme anxiety. A very good reliability and internal consistency of the items in thequestionnaire were obtained according to the Cronbach's alpha at 0.833 .

\section{Statistical analysis:-}

Data were analyzed by using Statistical Package for Social Studies (SPSS 22; IBM Corp., New York, NY, USA). Continuous variables were expressed as mean \pm standard deviation and categorical variables were expressed as percentages. The t-test was used for continuous variables. The Cronbach's alpha was used to assess reliability and internal consistency of the items in the questionnaire, the Cronbach's alpha was scored at 0.833 . P-value <0.05 was considered statisticallysignificant.

\section{Results:-}

This study was conducted on 190 patients after performing their operations; the females were dominant in this study than males where the male number was $85(44.74 \%)$ while female number was $105(55.26 \%)$. The mean age of participantswas33.10 \pm 9.81 , most of them were Saudi $176(92.63 \%)$ and only $14(7.37 \%)$ were non Saudi. Most of individuals were from Urban areas 185 (97.37\%) and high educational level $126(66.32 \%)$ while those from rural areas were $5(2.63 \%)$ only and secondary school education or less level was $64(33.68 \%)$. The results of questions were represented by mean \pm SD. Anxiety scoring started from zero which means no anxiety ascending to reach 10 which mean the maximum anxiety, the mean of each question for this study did not exceed 5. In the present study, no awaking was the more concern in patients (mean =4.91)followed by fearing of physical and mental harm after operation (mean=4.78) then awareness during anesthesia (mean=4.58), the next concern was post-operative pain (mean=4.54), however the last fearing was being at mercy of medical stuff (mean=3.11), while post-operative nausea and vomiting (mean=3.97) was higher than waiting for surgery (Mean=3.56). The results of questionnaire are summarized in table 1 for all subjects and regarding sex. 
Table 1:- Mean of each question in the questionnaire for all subjects and each gender

\begin{tabular}{|l|l|l|l|l|l|}
\hline \multirow{2}{*}{$\begin{array}{l}\text { Item } \\
\text { number }\end{array}$} & Statement & $\begin{array}{l}\text { All subjects } \\
\mathrm{N}=190\end{array}$ & Male N=85 & Female N=105 & $*$ P-value \\
\cline { 2 - 5 } Q1 & Mean(SD) & Mean(SD) & Mean(SD) & \\
\hline Q2 & $\begin{array}{l}\text { Being at the mercy of medical } \\
\text { staff }\end{array}$ & $3.11(2.80)$ & $3.00(2.00)$ & $3.19(3.32)$ & 0.047 \\
\hline Q3 & Results of the operation & $4.04(3.18)$ & $4.28(2.76)$ & $3.84(3.49)$ & 0.626 \\
\hline Q4 & Postoperative pain & $4.56(2.84)$ & $4.39(2.36)$ & $4.70(3.19)$ & 0.328 \\
\hline Q5 & Discomfort after the operation & $4.53(2.75)$ & $4.92(2.17)$ & $4.21(3.12)$ & 0.447 \\
\hline Q6 & $\begin{array}{l}\text { Postoperative nausea and } \\
\text { vomiting }\end{array}$ & $3.97(2.92)$ & $4.88(2.71)$ & $3.24(2.88)$ & 0.067 \\
\hline Q7 & $\begin{array}{l}\text { Not knowing what is } \\
\text { happening }\end{array}$ & $4.54(3.09)$ & $5.62(2.82)$ & $3.67(3.04)$ & $<0.001$ \\
\hline Q8 & $\begin{array}{l}\text { Physical/mental harm after the } \\
\text { operation }\end{array}$ & $4.78(3.91)$ & $6.44(3.67)$ & $3.44(3.59)$ & $<0.001$ \\
\hline Q9 & $\begin{array}{l}\text { No awakening from anesthesia } \\
\text { Q10 }\end{array}$ & $4.91(4.06)$ & $6.38(3.82)$ & $3.72(3.87)$ & $<0.001$ \\
\hline Total score for all items out of 100 & $42.57(23.60)$ & $49.25(22.27)$ & $37.17(23.36)$ & $<0.001$ \\
\hline
\end{tabular}

$*$ P-value $<0.05$ was considered statistically significant.

An assessment for anxiety score was performed to investigate the anxiety level of patients before surgery. Sever anxiety at a range of 76-100 represents 58 (30.53\%) of individuals in this study, while higher percent of persons experienced a moderate anxiety $72(37.89 \%)$ at rang of 51-75 of scores, mild anxiety at arrange of 25-50 was in 60 (31.58\%) of participants, all subjects suffered from anxiety with different degrees, table2.

Table 2:-Assessing Anxiety score of patients before surgery

\begin{tabular}{|l|l|l|l|}
\hline Range ofscore & Interpretationofscore & \multicolumn{1}{|c|}{ Frequency(\%) } & \\
\hline $76-100$ & Severe Anxiety & 58 & $(30.53)$ \\
\hline $51-75$ & Moderate & 72 & $(37.89)$ \\
\hline $25-50$ & Mild & 60 & $(31.58)$ \\
\hline$<25$ & None to slight & 0 & $(0.00)$ \\
\hline
\end{tabular}

\section{Discussion:-}

Anxiety is a usual reaction to stress and it is common in candidates for surgery (Jafar et al, 2012). It is known as preoperative anxiety. Preoperative anxiety is related to an alteration in neuroendocrine response which cause deleterious postoperatively ( $\mathrm{Ai}$ et al, 2005; Pearson et al, 2005).Improving surgical outcome related to reducing preoperative anxiety (Roomruangwonget al, 2000). An ideal assessing tool for preoperative anxiety must be short, easy, reliable and accurate tool to measure anxiety. Visual Analogue Scale (VAS) questionnaire is valid to measure anxiety (Matthiaset al, 2012) because it is short, easy, simple and reliable for the measurement of preoperative anxiety (Elkins et al, 2004; Kindler et al, 2000), for these reasons we used VAS in this study to assess anxiety. The most common reasons for preoperative anxiety are fearing of mistakes in operation that can harm patients, this reason represents $64 \%$, fearing fromnot waking up and represents $58.4 \%$ and only $8 \%$ represents worrying about post-operative nausea and vomiting (Nigussie et al, 2014). Also waiting for operation, worrying about the physical and mental harm (Perks et al, 2009), fear of the surgery and postoperative pain (Caumo et al, 2001)are reported. In a study by Kindler et al (Kindler et al, 2000), they found that waiting for the operation, being at the mercy of medical staff, result of the operation and postoperative pain were the first to fourth respectively in order as causes of anxiety, however in our study these four reasons ranked in different order. No awaking, physical and mental harm after operation, awareness during anesthesia and post-operative pain were the top reasons of anxiety respectively in our patients, while being at the mercy of medical staff was the last one. The concern about not awaking was the first reason for anxiety in our study, this may be due to low level of awareness of patients about operation nature and the development in operation techniques. In a study of United States (Bondy et al, 1999), it was reported that the 
preoperative anxiety was reduced by giving information to the patients about procedures. Kiyohara et al (2004)study showed that patients, who received information about the surgical procedure, had lower anxiety levels. Also a study in India (Vandana et al, 2009), reported the same results about developing less preoperative anxiety from patients who received information about surgery than those who were not informed, so providing patients with information about disease and operation will decrease preoperative anxiety. Awareness during anesthesia was one of the 4 top concerns causing anxiety, actually it was the third in order, so it is important to increase patient awareness about anesthesia technique and safety by visiting anesthesiologist before surgery to decrease their fearing. The last reason in the presentstudywasbeingatthe mercyofmedicalstaff, whilestudy by Kindler et al (2000) showed that last concern was awareness during anesthesia, this differences in results may returns to differences in culture, public awareness and education levels, although there is difference in ordering of anxiety reasons, preoperative anxiety still exist whatever its cause. In a study by Jawaid et al (2007)and MacClean et al (1990), they reported that patient's highest concern was post-operative pain, while in the present study its order wasnumberfour. The $7^{\text {th }}$ concern in our patients was the results ofoperation, while in a study by Akinsulore et al (2015), this reason was the first in their patients and the third in Jawaid study (Jawaid et al, 2007). A study in Port Harcourt Teaching Hospital in southeastern Nigeria (Ebirim et al, 2010)and a study by Nigussie et al (2014), they found that Worrying about postoperative nausea and vomiting was the last concern of patients, this is near to our findings in the current study where this concern ranked the $8^{\text {th }}$ one of 10 concerns. Many studies (Saini et al, 2016; Perks et al, 2009; Jawaid et al, 2007; Norris et al, 1967; Karanci et al, 2003)reported that female gender is one of many factors associated with preoperative anxiety. In a by study Yilmaz et al (2011), they reported that anxiety scores were higher among females than males. Additionally Jafar and Khan(2012) found that Females were moreanxious than males with preoperative anxiety, these results are in agreement with ours. In the present study females experienced more anxiety than males $(\mathrm{P}$-value $<0.001)$. However Nishimori et al (2002) showed that there is no association between gender and anxiety. Also another studies (Hernández-Palazón et al, 2015;Navarro-García et al, 2011) reported that there was no significant difference between males and females regarding the incidence of anxiety. Several studies (Matthias et al, 2012; , Nishimori et al, 2002; Berth et al, 2007; Sirinan et al, 2000)mentioned that Females were more anxious about anesthesia than males, this in agreement with our study, where females had a fear of no awaking from anesthesia and awarenessduringanesthesia than males. By assessing anxiety in this study, we found that moderate anxiety was dominant in patients $(37.89 \%)$ while mild anxiety was experienced by $31.58 \%$ of our patients, severe anxiety represented $30.53 \%$ of the individuals of this study. In study by (Kalkhoran et al, 2007), they found that $66.7 \%$ of patients had moderate anxiety. Other studies reported that surgical patients have moderate to severe anxiety (Karanci et al, 2003; Yardakc et al, 2004; Akkas et al, 2004).

\section{Conclusion:-}

In conclusion, preoperative anxiety is very common in candidates of surgery but with different degrees. Females are more anxious than males, so it is important to decrease patient anxiety before operation.

\section{References:-}

1. Ai, A.L., Kronfol, Z., Seymour, E. and Bolling, S.F. (2005): Effects of mood state and psychosocial functioning on plasma Interleukin-6 in adult patientsbefore cardiac surgery. Int.J.Psychiatry Med., 35(4):363-76.

2. Akinsulore, A., Owojuyigbe, A.M., Faponle, A.F. and Fatoye, F.O. (2015): Assessment of preoperative and postoperative anxiety among elective major surgery patients in a tertiary hospital in Nigeria. Middle East J. Anaesthesiol,23(2).

3. Akkas, Gu“ rsoy A. (2004):To determine the anxiety levels and the factors which may cause anxiety in preoperative surgical patients. Journal of Nursing Research Development (HEMAR- G), 1: 23-29.

4. Badner, N.H., Nielson, W.R., Munk, S., Kwiatkowska, C. and Gelb A.W. (1990): Preoperative anxiety: detection and contributing factors. Can. J. Anaesth., 37:444-7.

5. Berth, H., Petrowski, K. and Balck, F. (2007): The Amsterdam Preoperative Anxiety and Information Scale (APAIS) - the first trial of a German version. Psychosoc. Med., 4:Doc01.

6. Boker, A., Brownell, L. and Donen, N. (2002): The Amsterdam preoperative anxiety and information scale provides a simple and reliable measureof preoperative anxiety. Can.J.Anaesth., 49(8):792-8.

7. Bondy, L.R., Sims, N., Schroeder, D.R., Offord, K.P. and Narr, B.J. (1999): The effect of anesthetic patient education on pre-operative patient anxiety. Reg. Anest. Pain Med., 24: 158-164.

8. Caumo, W., Schmidt, A.P., Schneider, C.N., Bergmann, J., Iwamoto, C.W., Bandeira, D. et al. (2001): Risk factors for preoperative anxiety in adults. ActaAnaesthesiologicaScandinavica, 45,298-307.

9. Domar, A. D., Everett, L.L., Keller, M.G. (1989): Preoperative anxiety: is it a predictable entity? AnesthAnalg, 
69:763-7.

10. Ebirim L and Tobin M: Factors Responsible For Pre Operative Anxiety In Elective Surgical Patients At A University Teaching Hospital: A Pilot Study. Internet J Anesthesiol, 2010:29:2.

11. Elkins, G., Staniunas, R., Rajab, M.H., Marcus, J. andSnyder, T. (2004). Use of a Numeric Visual Analog Anxiety Scale Among Patients Undergoing Colorectal Surgery. Clin.Nurs.Res., 13:237-244.

12. Hernández-Palazón, J., Fuentes-García, D., Falcón-Araña, L. and Falcón-Araña, M.J. (2015): Visual Analogue Scale for Anxiety and Amsterdam Preoperative Anxiety Scale Provide a Simple and Reliable Measurement of Preoperative Anxiety in Patients Undergoing Cardiac Surgery. IntCardiovasc Res J., 9(1):1- 6.

13. Jafar, M.F. and Khan, F.A. (2012): Frequency of preoperative anxiety in Pakistani surgical patients. Journal of the Pakistan Medical Association, 59(6):359-63.

14. Jawaid, M., Mushtaq, A., Mukhtar, S. andKhan, Z. (2007): Preoperative anxiety before electivesurgery. Neurosciences, 12 (2):145-148.

15. Johnston, M.(1989): Anxiety in surgical patients. Psychol Med,10:145-52.

16. Kalkhoran, M.A. and Karimollahi, M. (2007): Religiousness and preoperative anxiety: a correlational study. Annals ofGeneral Psychiatry, 29:6-17.

17. Karanci,A.N. and Dirik, G. (2003): Predictors of pre- and postoperative anxiety in emergency surgery patients. Journal of Psychosomatic Research, 55,363-369.

18. Kim, W.S., Byeon, G.J., Song, B.J. and Lee, H.J. (2010): Availability of preoperative anxiety scale as a predictive factor for hemodynamic changes during induction of anesthesia. Korean J Anesthesiol, 58(4):328333

19. Kindler, C.H., Harms, C., Amsler, F., Ihde-Scholl, T. and Scheidegger, D. (2000): The visual analog scale allows effective measurement of preoperative anxiety and detection of patients' anesthetic concerns. AnesthAnalg, 90(3):706- 12.

20. Kiyohara, L.Y., Kayano, L.K., Oliveira, L.M., Yamamoto, M.U., Inagaki, M.M., Ogawa, N.Y. et al. (2004): Surgery information reduces anxiety in the pre-operative period. Rev.Hosp.Clin.Fac.Med. S. Paulo, 59: 51-56.

21. Klopfenstein, C.E., Forster, A. and Van Gessel, E. (2000): Anesthetic assessment in an outpatient consultation clinic reduces preoperative anxiety. Can.J.Anesth., 47:511-515.

22. Maranets, I. and Kain, Z.N. (1999): Preoperative anxiety and intraoperative anesthetic requirements. AnesthAnalg., 89(6):1346-51.

23. Martin, C.R., Thompson, D.R. and Chan, D.S.K. (2004): An examination of the psychometric properties of the Hospital Anxiety and Depression Scale in Chinese patients with acute coronary syndrome. Psychiatry research, 129(3):279-88.

24. Matthias, A.T. and Samarasekera, D.N. (2012): Preoperative anxiety in surgical patients - experience of a single unit. ActaAnaesthesiologicaTaiwanica, 50:3-6

25. McCleane, G.J. and Cooper, R. (1990): The nature of preoperative anxiety. Anaesthesia,45:153-155.

26. Millar, K., Jelicic, M., Bonke, B. andAsbury, A.J. (1995): Assessment of preoperative anxiety: comparison of measures in patients awaiting surgery forbreast cancer. Br.J.Anaesth,74(2):180-3.

27. Navarro-García, M.A., Marín-Fernández, B., de Carlos-Alegre, V., Martínez-Oroz, A., Martorell-Gurucharri, A., Ordoñez-Ortigosa, E., et al. (2011): Preoperative mood disorders in patients undergoing cardiac surgery: risk factors and postoperative morbidity in the intensive care unit. Rev. Esp. Cardiol.,64(11):1005-10.

28. Nigussie, S., Belachew, T. and Wolancho, W. (2014): Predictors of preoperative anxiety among surgical patients in Jimma University Specialized Teaching Hospital, South Western Ethiopia. BMC Surgery,14:67.

29. Nikumb, V.B., Banerjee, A., Kaur, G. and Chaudhury, S. (2009): Impact of doctor-patient communication on preoperative anxiety: Study at industrial township, Pimpri, Pune. Ind. Psychiatry J., 18(1):19-21.

30. Nishimori, M., Moerman, N., Fukuhara, S., van Dam, F.S.A.M., Muller, M.J., Hanaoka, K., et al. (2002): Translation and validation of the Amsterdam preoperative anxiety and information scale(APAIS) for use in Japan. Quality of Life Research, 11:361-364.

31. Norris, W. and Baird, W.L.M. (1967): Preoperative anxiety: a study of the incidence and aetiology. Br.J. Anaesth., 39,503-509.

32. Oddershede, L., Andreasen, J.J. and Ehlers, L. (2014): Estimation of utility values from visual analog scale measures of health in patients undergoingcardiac surgery. Clinicoecon. Outcomes Res., 6:21-7.

33. of Nursing Research Development (HEMAR-G), 6: 7-14.

34. Perks, A., Chakravarti, S. and Manninen, P. (2009): Preoperative anxiety in neurosurgical patients. J.Neurosurg.Anesthesiol., 21(2):127-30.

35. Pochard, F., Bellivier, F. and Squara, P. (1996): Prevalence and prognostic value of anxiety and depression in patients undergoing cardiacsurgery. European Psychiatry, 11:326s. 
36. Roomruangwong, C., Tangwongchai, S. and Chokchainon, A. (2012): Preoperative Anxiety among Patients Who Were about to Receive Uterine Dilatation and Curettage. J Med Assoc Thai., 95 (10).

37. Saini, S. and Dayal, M. (2016): Preoperative Anxiety in Indian Surgical Patients- Experience of a Single Unit. Indian Journal of AppliedResearch, 6(9).

38. Shafer,A., Fish, M.P., Gregg,K.M., Seavello, J. and Kosek, P. (1996). Preoperative anxiety and fear: a comparison of assessments by patients and anesthesia and surgery residents. Anesth.Analg., 83(6):1285-91.

39. Underwood M.J., Firmin R.K. and Jehu D. (1993): Aspects of psychological and social morbidity in patients awaiting coronary artery bypass grafting. Br. Heart. J., 69(5):382-4.

40. Yardakc,I. R. and Akyolcu, N. (2004): The effect of the visits made preoperative period on the patients'anxiety level.Journal

41. Yilmaz, M., Sezer, H., Gürler, H. and Bekar, M. (2011): Predictors of preoperative anxiety in surgical inpatients. Journal of Clinical Nursing, 21: 956-964 